\title{
El endometrio en la infertilidad. Histología y fechado endometrial
}

\author{
Constanza Díaz Calle*; Fabio Sánchez Escobar**
}

\begin{abstract}
RESUMEN: El procedimiento de la biopsia de endometrio es muy discutido para el diagnóstico de ovulación máxime si se relaciona con la determinación de la progesterona en sangre. Sinembargo en nuestra experiencia consideramos este procedimiento muy útil, no sólo para aproximarse al diagnóstico de cuerpo lúteo insuficiente sino para diagnosticar otras patologías tales como estenosis y pólipos endocervicales, además de patología uterina y endometrial macro o microscópica.
\end{abstract}

Se hace una descripción breve sobre los fenómenos que ocurren durante el proceso de maduración endometrial a lo largo del ciclo menstrual y los diferentes patrones utilizados para el fechado endometrial; finalmente se propone un método objetivo para medir la maduración endometrial, útil para la investigación, basándose en la medición de variables cualitativas que hacen parte de los cambios a través del ciclo.

PALABRAS CLAVES: Endometrio, fechado endometrial, histología del endometrio.

SUMMARY: Endometrial biopsy is a controversial technique for the determining ovulation specially when the result is to be correlated with plasma progesterone. In our experience however this procedure has been useful for diagnosing corpus luteum insuficciency and other pathologies such as endocervical stenosis and polyps, and other macro and microscopic endometrial pathologies.

This article includes a short description of the phenomena ocurring during the process of endometrial maturation along the menstrual cycle and the different profiles used for endometrial dating. An objective method for measuring endometrial maturation is proposed which is based on the measure of qualitive change ocurring through the cycle.

KEY WORDS: Endometrium, endometrial dating, endometrial histology.

El examen histológico del endometrio es muy útil para el estudio de la infertilidad de causa endocrina, al actuar de bioensayo con relación a la producción de progesterona (1-2). A pesar de ser un procedimiento discutido por muchos investigadores (3), nuestra experiencia ha demostrado su validez, máxime si se correlaciona con otros procedimientos diagnósticos. En una investigación efectuada en nuestro Departamento, en 16 mujeres en etapa fértil, se pudo apreciar una correlación (Rho) significativa entre el endometrio secretor y el cuerpo lúteo de 0.8635 , en tanto no existe por el contrario una buena correlación entre el cuerpo lúteo y la pogesterona en donde sólo alcanzó Rho de 0.1814 y una $\mathrm{P}<0.5532$ (4).

El procedimiento de la biopsia no sólo es útil para el diagnóstico de la posible ovulación, sino que permite conocer durante el procedimiento, la presencia de patología insospechada tal como estenosis cervical, patología de la cavidad uterina tales como adherencias, miomas, pólipos, malformaciones y miohipertrofia; además el estudio histológico informa sobre la presencia de endometritis aguda o crónica y la presencia de restos ovulares (5) (Tabla 1).

\footnotetext{
* Profesora Titular Departamento Anatomía Patológica.

** Profesor Titular Departamento Obstetricia y Ginecología. Grupo de Ginecología Endocrina y Reproducción Humana y Centro de Investigaciones Médicas.
}

Tabla 1

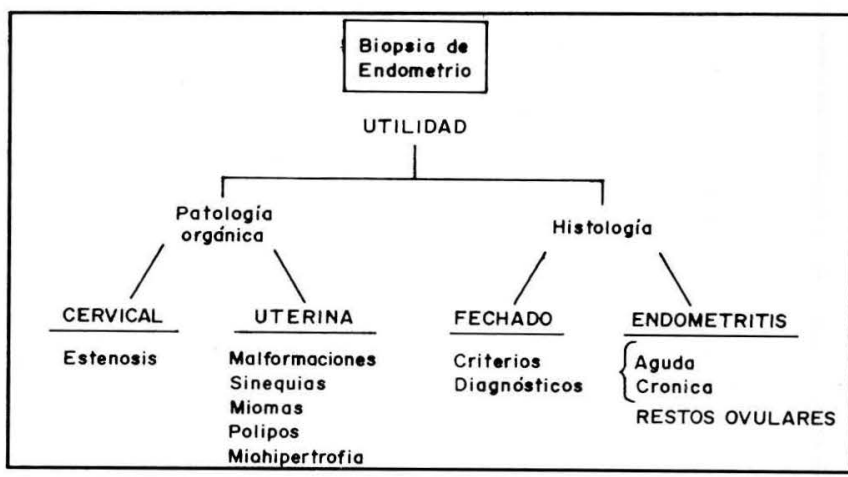

La toma de la biopsia de endometrio se programa preferiblemente dos a cinco días antes de la próxima menstruación, aunque se puede tomar en cualquier fecha de la fase secretora; no es necesario prescribir métodos anticonceptivos. Durante el procedimiento se utiliza la cureta de Novak, previa asepsia vaginal y cervical y sólo se necesita pinza de cuello en casos especiales. La biopsia se toma del fondo uterino y de las paredes laterales, en su porción superior, lugar donde hay mayor maduración endometrial, mayor vascularización y mayor número de receptores (6-7).

Aunque las probabilidades de embarazo son escasas en una pareja que consulta por infertilidad ( 3 a $5 \%$ ) y de interrumpirlo de 0.067 a menos del $2 \%$ (6). En el caso de que 
la paciente esté en embarazo, el trauma ocasionado por la biopsia tendría más un efecto benéfico, según nuestra experiencia, la cual coincide con la de otros investigadores, en donde en un $11 \%$ de los embarazos en parejas infértiles ocurrió durante el ciclo de la biopsia (8-9).

Múltiples son las hipótesis que se tienen con respecto a este fenómeno, Karow quien postula que la biopsia desencadena una reacción decidual como efecto local a cambios endocrinos secundarios al efecto mecánico a nivel cervical, mecanismo que facilita la implantación ovular (10-11), el cual ha sido especial motivo de nuestra investigación efectuado con humanos, con el modelo experimental, es así como se ha podido demostrar como la biopsia de endometrio no desencadena ningún tipo de reflejo endocrino a nivel vaginal o cervical que modifique la secreción de FSH, LH y PRL (12), en tanto si se demostró cambios importantes a nivel local tal como edema universal del endometrio hasta bloquear la cavidad, presencia de granulocitos estromales y ausencia de células deciduales (13), a diferencia de lo encontrado en ratas por otros investigadores quienes describen abundante reacción decidual (14).

Quienes postulan el efecto benéfico de la biopsia de endometrio, hablan de la liberación de la anhidrasa carbónica (11) de histamina liberada por los mastocitos o de prostaglandinas que producen mayor vascularización y reacción decidual (14).

\section{Histología del endometrio}

El endometrio es el tejido que recubre la superficie interna de la cavidad uterina. Se deriva del endodermo, es el tejido más dinámico y sensible del organismo. Tiene la propiedad de responder a la acción de hormonas esteroideas (estrógenos y progesterona). Cuando la secreción es cícli$\mathrm{ca}$, como ocurre en la mujer con ciclos ovulatorios, responde con cambios de proliferación, secreción, descamación y necrosis, según sea el estímulo hormonal.

Durante la fase proliferativa, alcanza el máximo crecimiento como resultado de la mayor actividad mitótica de las células epiteliales y alcanza a medir hasta $10 \mathrm{~mm}$ de espesor alrededor de la tercera semana. Pero en la fase secretora avanzada, una vez ocurre la máxima secreción de progesterona, se detiene esta actividad como consecuencia de su acción antiproliferativa, por lo cual se reduce el espesor del endometrio a partir de la tercera semana en adelante (15) y en donde posiblemente sea potenciada por el interferón sintetizado por células del estroma (16).

Desde el punto de vista histológico se pueden distinguir dos capas bien definidas:

1. Una capa basal permanente o regenerativa que permanece desde la niñez hasta la senectud.

2. La capa funcional o glandular, que descama cíclicamente. Esta capa está conformada a la vez por un estrato compacto o superficial y uno profundo o esponjoso.

1. En la capa basal, el epitelio está constituido por células poliédricas bajas y poco activas. Esta capa tiene menos actividad mitótica posiblemente por la acción antiproliferativa del interferón, que se sintetiza a nivel del tejido linfoide en la base de la glándula (16). En tanto en el estroma, se aprecian los vasos sanguíneos o arterias rectas (que poseen un esfínter con propiedad de contraerse, como consecuencia de la caída simultánea de los niveles plasmáticos de estrógenos y progesterona y por la acción directa de la prostaglandina $\mathrm{F} 2$ alfa, leucotrienos, peróxidos, factor activador de plaquetas (PAF), interleukinas $1 \mathrm{~B}$, factor tumoral de necrosis, perforinas prostaciclinas, fibrinolisinas, heparina y otros mecanismos que dan origen a la menstruación (17).
2. La capa funcional se origina de la capa basal y prolifera como consecuencia de la acción de los estrógenos plasmáticos, cuando alcanza niveles por encima de $30 \mathrm{pg} /$ $\mathrm{ml}$. Inicialmente el endometrio es proliferativo y luego se transforma en secretor por acción de la progesterona.

$\mathrm{Al}$ terminar la fase proliferativa, la capa funcional del endometrio se puede dividir en:

a. Capa superficial o compacta que corresponde a los cuellos glandulares.

b. Capa profunda o esponjosa conformada por los cuerpos glandulares.

La capa funcional descama y se reabsorbe durante la época menstrual y posteriormente se regenera a partir de la capa basal.

Si se observa la histología del endometrio, se puede apreciar que la capa funcional está constituida por dos elementos principales: el epitelio glandular y el estroma, con funciones especializadas específicas para el momento de la anidación y desarrollo del embrión.

1. El epitelio glandular: está constituido por una capa única de células columnares cuya altura varía desde 6 micras en la fase premenstrual hasta 20 en la fase proliferativa avanzada. El epitelio inicialmente está conformado por células cilíndricas que luego forman varios estratos (seudoestratificación) y finalmente se hacen columnares, como consecuencia de la acción estrogénica. Durante la fase proliferativa, en las células epiteliales hay mayor actividad mitótica, mayor síntesis de RNA, el cual se almacena a nivel del citoplasma y hacia el final de esta fase se observan abundantes ribosomas, se hace visible el aparato de Golgi y las mitocondrias se multiplican y se agrandan. Posteriormente, por acción de la progesterona se almacenan gotas de glicógeno, mucopolisacáridos, proteínas y lípidos en el citoplasma, lo que da origen en un principio a las vacuolas subnucleares en un porcentaje que afectan más del $50 \%$ de las células. Los núcleos durante la fase proliferativa son alargados con cromatina densa, crestas compactas y filamentos intramitocondriales de DNA, que se transforman en redondos y ovales con disminución gradual de DNA, en la fase secretora.

Para el día 19 ó $20,5^{\circ}-6^{\circ}$ postovulación (PO) la membrana celular forma microvellosidades cargadas con productos de secreción, que horas después, la célula excreta junto con su borde apical (secreción apocrina) y se hacen más pequeñas (cúbicas). La secreción de las glándulas está constituida por restos de células epiteliales, proteínas, mucopolisacáridos ácidos y neutros, fosfátidos, glicógeno y enzimas.

El endometrio está recubierto por dos clases de células epiteliales, unas con microvellosidades o cilias y otras sin ellas; la mayor población de células ciliadas está en la región cornual y el endocérvix, siendo su localización principalmente al nivel del ostium de la glándula; estas cilias decrecen durante la fase secretora.

2. Tejido estromal. Está constituido por células pluripotenciales que se originan del mesénquina. Tiene forma de huso y están unidas entre sí por una fina red. Sus núcleos son densos, con formas de bizarras y el citoplasma es escaso.

Durante la fase proliferativa, las células estromales permanecen inactivas y sólo las mitosis se inician en la mitad de la fase secretora, coincidiendo con la máxima secreción de progesterona, cuando se transforman en célula decidual o en granulocitos.

a. La célula decidual, aparece a partir del día noveno P.O., tres o cuatro días después de haber ocurrido el 
máximo edema; éstas células se localizan inicialmente en forma difusa, luego alrededor de los vasos y finalmente debajo del epitelio columnar colonizando gran parte del estroma. Tiene la capacidad de sintetizar prostaglandinas y principalmente prolactina.

En cultivo de tejidos se ha apreciado que la progesterona es la única hormona capaz de producir decidualización en el estroma endometrial, proceso que al parecer es mediado por la proteína dependiente de progesterona (PEP) (18).

B. Los granulocitos estromales, son células pequeñas, redondas, con núcleos densos, que se originarían de las células estromales, aunque algunos investigadores postulan su origen en la médula ósea. Aparecen desde el día décimo P.O., aunque desde el día seis se pueden demostrar en su citoplasma vacuolas de glicógeno, glicoproteína y gránulos floxinofílicos que son el resultado de la síntesis de una macromolécula rica en tirosina y triptofano, que se ha definido como relaxina (19). Esta hormona se libera una vez caen los niveles plasmáticos de progesterona o al adherirse el blastocito, fenómeno que hace que se aumente la permeabilidad de las membranas de los lisosomas por acción de dos enzimas colagenolíticas: la colagenasa y el activador del plasminógeno, fenómeno que facilita la implantación del blastocito. En el lugar donde se implanta el bastocito, se acumulan granulocitos que liberan relaxina, a diferencia del resto del endometrio donde la almacenan (20-21).

Los granulocitos se confunden con leucocitos, pero estos últimos sólo se encuentran en el momento en que se inician los fenómenos de descamación, además no poseen relaxina ni gránulos floxinofílicos.

En ocasiones se ven histiocitos que podrían llegar a tener funciones específicas como macófagos (siderófagos, lipófagos) que tienen su origen en la médula ósea y mastocitos, que se originan del propio estroma.

c. Los vasos de la capa funcional del endometrio se diferencian de los del resto del organismo por su estructura y rápida respuesta a las hormonas esteroides. Durante la fase proliferativa, las arterias espirales, ramas de las arterias rectas de la capa basal del endometrio, proliferan hasta hacerse tortuosas como consecuencia de su mayor desarrollo, con respecto a la proliferación del endometrio. Inicialmente delgadas, se alargan y dilatan hasta alcanzar la superficie e iniciar su tortuosidad, la que se hace mayor en la fase secretora; en esta época por acción de la progesterona, las paredes de los vasos proliferan, aumenta su grosor y la luz se dilata hasta constituir verdaderas lagunas vasculares por congestión. (Tabla 2).

\section{Tabla 2}

\section{ELEMENTOS HISTOLOGICOS DEL ENDOMETRIO}

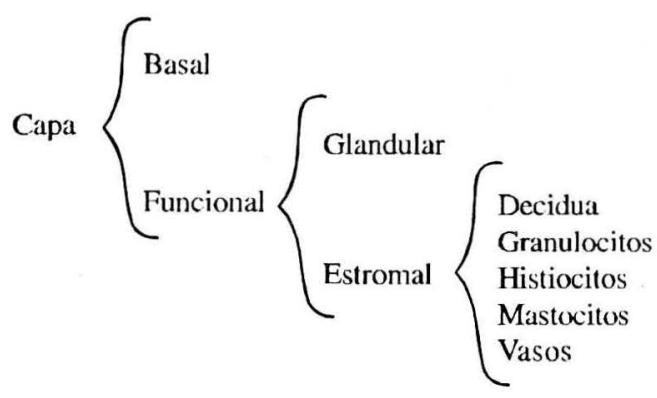

A partir del día décimo P.O., cuando ocurre la implantación, se presenta más hiperplasia en las paredes de los vasos, en tanto, cuando no se presenta fecundación y caen los niveles plasmáticos de estrógenos y progesterona, se libera la relaxina y prostaglandinas y como consecuencia hay lisis de las paredes de los vasos y presencia de hemorragias en parches en el estroma, horas antes de ocurrir la menstruación. Posteriormente los vasos recuperan su estructura original a partir de las arterias rectas.

\section{Fechado de endometrio}

El endometrio es un tejido dinámico, que se modifica periódicamente como consecuencia de los cambios cíclicos de las hormonas ováricas, lo que permite en el estudio histológico con hematoxilina-eosina, determinar el día del ciclo: (15-22), en ocasiones se complementa con otras técnicas especiales, tales como microscopio elctrónico, que ofrece detalles más precisos de la célula. Todos los cambios del ciclo ovárico se reflejan en este tejido que se comporta como un bioensayo, por lo cual lo hemos denominado como espejo endocrino.

Para fechar el endometrio se tiene en cuenta la zona de mayor avance en su maduración, pues éste fenómeno no es uniforme, sin embargo, la diferencia entre las áreas estudiadas no debe ser mayor de dos días. En el caso de que ocurra, se habla de maduración asincrónica. Además, elárea de mayor respuesta endometrial ocurre en el fondo uterino.

\section{Fase proliferativa}

La fase proliferativa corresponde a la etapa de maduración folicular, en condiciones fisiológicas tiene una duración de doce a catorce días, pero puede fluctuar entre diez y veinte días, es la fase más variable del ciclo menstrual.

El estudio histológico del endometrio difiere entre la fase proliferativa y la secretora, pues en la primera es imposible fecharlo por días, como sí ocurre en la fase secretora, debido a que sus cambios son menos definidos, por lo cual se divide para su informe en tres etapas: proliferativa inicial, proliferativa media y proliferativa tardía, cambios que ocurren por acción del influjo del estradiol.

\section{a. Fase proliferativa temprana o inicial:}

Cuarto a séptimo día de un ciclo patrón de 28 días.

El endometrio es un tejido muy delgado, de $1 \mathrm{~mm}$ de espesor, se reduce a una capa basal epitelializada en donde las glándulas son escasas como fondos de saco, tubulares con luz recta y estrecha, revestidas de células columnares bajas. Los núcleos son ovales y pequeños; los nucléolos poco aparentes; el estroma está constituido por células fusiformes laxas y hay red reticular fina y vasos delgados imperceptibles.

\section{b. Fase proliferativa media:}

Octavo a décimo día de un ciclo de 28 días.

Las glándulas incrementan su altura hasta hacerse tortuosas debido a su mayor proliferación con respecto al estroma; las células del epitelio glandular son altas, cilíndricas y aparecen como comprimidas. Los núcleos son grandes, ovales, elongados y densos, con gran actividad mitótica, los nucléolos se vuelven aparentes; el estroma se torna laxo y edematoso, con células fusiformes, con escaso citoplasma y abundantes mitosis.

\section{c. Fase proliferativa tardía:}

Decimoprimero a decimocuarto día de un ciclo de 28.

El cambio más notorio en esta fase es la desaparición del edema en el estroma, como consecuencia se contrae y las glándulas se ven tortuosas; las células epiteliales continúan 
proliferando, pero todas conservan su unión con el estrato basal epitelial, lo que da un aspecto estratificado que no es real (pseudoestratificación), los bordes apicales de las células no son nítidos y aparecen desflecados. Los núcleos son basales. La aparición de granos finos de glucógeno demostrables con la coloración de PAS, son la manifestación precoz de la acción de la progesterona en la mitad del ciclo. Además se pueden observar escasas vacuolas subnucleares que no alcanzan al $50 \%$ de las células epiteliales; el estroma es denso, constituido por células fusiformes que se aumentan en número y tamaño, las arterias espirales tienen paredes delgadas, son poco aparentes.

\section{Fase secretora}

Una vez que ocurre la ovulación y se inicia la formación de el cuerpo lúteo, se desencadena una serie de cambios histológicos promovidos por la progesterona. La fase lútea tiene una duración un poco más estable, doce a catorce días, pero puede variar entre 9 y 17 días. Cuando su duración es menor de doce días, se debe sospechar la presencia de un cuerpo lúteo insuficiente.

En el endometrio secretor se pueden apreciar los cambios histológicos día a día, lo que permite determinar la fecha postovulatoria (P.O.). Esta fecha sumada a los catorce días convencionales de la fase proliferativa, permite hablar del día histológico con respecto a un ciclo de 28 días y se puede así correlacionar con la fecha cronológica.

\section{Día 1 P.O. (Día 15 del ciclo)}

Es un día mudo, se aprecian modificaciones histológicas específicas. Estas sólo se expresan 24 horas después de la ovulación. Las células epiteliales pueden presentar vacuolas ocasionales en la base de la célula; la aparición de gotas de glucógeno no es signo inequívoco de acción progestacional.

\section{Día 2 P.O. (Día 16 del ciclo)}

Las células epiteliales forman una fila única alrededor de la luz de las glándulas. Estas a su vez aumentan en altura y dan la apariencia de sacacorchos, las vacuolas se localizan en casi todas las células en la base y se rechazan los núcleos hacia el centro.

En el estroma se pueden observar escasas hemorragias que pueden dar origen a las pintas post-ovulatorias o signo de Hartman, que se correlaciona con la caída de los estrógenos circulantes al momento de la ovulación.

\section{Día 3 P.O. (Día 17 del ciclo)}

Las células epiteliales pierden su capacidad de mitosis y se aumenta la actividad secretora. Se altera la relación núcleo-citoplasma. Las vacuolas subnucleares rechazan todos los núcleos hacia el centro a diferentes niveles dando la apariencia de un teclado de piano. Estas vacuolas son claras, ricas en glucógeno y lípidos.

\section{Día 4 P.O. (Día 18 del ciclo)}

Las vacuolas se van desplazando hacia la porción apical de la célula y se observan rodeando los núcleos, los cuales regresan a su posición basal.

\section{Día 5 P.O. (Día 19 del ciclo)}

La totalidad de los núcleos regresan a su posición basal, en tanto las vacuolas de secreción están en su localización apical y dan origen a un abombamiento del borde apical de la celular, se inicia la secreción hacia la luz de la glándula por lo cual se aprecia pérdida de la nitidez del borde luminal. Los núcleos de las células son claros por disminución de RNA, los nucléolos se hacen más evidentes.

\section{Día 6 P.O. (Día 20 del ciclo)}

Se aprecia dilatación de la luz glandular por el contenido de secreción, el borde de las células es desflecado, difuso, irregular, como consecuencia de la pérdida de un poco de su citoplasma, secreción apocrina. Hasta este momento del ciclo, las células del estroma tienen un aspecto fusiforme con citoplasma poco aparente y con contornos mal definidos como consecuencia de su escasa actividad.

\section{Día 7 P.O. (Día 21 del ciclo)}

A partir de este día se inician cambios en el estroma y sin modificaciones sustanciales del epitelio glandular, que continúa siendo estable durante el resto del ciclo. En este día, el epitelio glandular se contrae por la desaparición de la secreción luminal, mientras el estroma es laxo por la presencia de focos de edema.

\section{Día 8 P.O. (Día 22 del ciclo)}

Se aprecia el máximo edema en el estroma, hecho que concuerda con la máxima concentración de progesterona en plasma. El estroma es laxo, aumenta su volumen, los vasos empiezan a elongarse y proliferar.

\section{Día 9 P.O. (Día 23 del ciclo)}

Al disminuir el edema, las arterias espirales se hacen prominentes debido a que proliferan y se engruesa. Las células del estroma alrededor de los vasos se transforman en células deciduales que aumentan en tamaño; se tornan redondeadas o poliédricas con citoplasma abundante, núcleos grandes, redondos y claros.

\section{Día 10 P.O. (Día 24 del ciclo)}

Las arterias se encuentran engrosadas, proliferadas y congestivas rodeadas por acúmulos de células deciduales a su alrededor, conformando un manguito. Además aparecen granulocitos pequeños con escaso citoplasma y núcleo denso (granulocitos estromales).

\section{Día 11 P.O. (Día 25 del ciclo)}

Las células deciduales se difunden por todo el estroma, tal como alrededor de las arteriolas proliferadas y en la zona subepitelial del estroma, en forma de parches confluentes que dan la apariencia de empedrado. Su citoplasma es rico en glicógeno (PAS +).

\section{Día 12 P.O. (Día 26 del ciclo)}

La capa compacta está totalmente decidualizada, los vasos proliferados y congestivos, dan origen a lagunas debajo del epitelio superficial. Hay más granulocitos estromales.

\section{Día 13 P.O. (Día 27 del ciclo)}

Las glándulas se colapsan, la parte apical tiene la forma dentada, el estroma se contrae, aparecen infiltrado de leucocitos de origen vascular. Los vasos presentan lisis focal de la pared con parches de extravasación, como consecuencia de la caída de los niveles plasmáticos de progesterona y estradiol.

\section{Día 14 P.O. (Día 28 del ciclo)}

Hay desintegración total de la capa funcional, necrosis del estroma, disolución de las fibras reticulares, lisis vascular y epitelial, restos nucleares y hemorragia.

\section{Etapa menstrual}

La fase menstrual comprende desde el día primero al tercero del ciclo: en este momento el endometrio tiene un espesor de $0.5 \mathrm{~mm}$.

\section{Día 1}

Se aprecian hemorragias en la capa esponjosa a nivel del estroma, acompañada de colapso glandular, en este mo- 
mento aún es posible apreciar en el tejido cambios compatibles con endometrio secretor.

\section{Día 2}

Se aprecian restos de epitelio glandular, focos de hemorragia reciente en el estroma, células deciduales diseminadas. No es posible para el patólogo definir si fue o no un endometrio secretor.

\section{Día 3}

Es la fase de reepitelización del endometrio que ocurre entre el segundo y tercer día y se hace a espensas de la capa basal, fenómeno que no es exclusivo de la acción hormonal.

El fechado histológico del endometrio tiene su utilidad en el estudio de la pareja infértil y principalmente en el estudio del factor endocrino.

El informe de un endometrio proliferativo se asocia a trastornos del ciclo, alteraciones endocrinas y anovulación crónica, compatibles con diagnóstico de un síndrome de ovario androgénico.

La verdadera importancia de la biopsia de endometrio está dada en el diagnóstico del cuerpo lúteo insuficiente, en donde al comparar el día histológico del endometrio con respecto al día cronológico, se aprecia un retardo en la maduración de dos o más días en dos o más ciclos sucesivos (1-23).

Para definir el día cronológico, no hay un consenso con respecto a los diversos autores; mientras algunos conceptúan que el día 28 del ciclo es el día anterior a la menstruaciốn siguiente a la toma de la biopsia de endometrio, otros afirman como día 28 el mismo día de la menstruación; en nuestro servicio se acepta el primer criterio.

Para poder fechar adecuadamente el endometrio, la paciente debe menstruar dentro de los doce días de la toma de la biopsia, teniendo en cuenta que la fase lútea dura catorce días, dos de los cuales son mudos histológicamente.

Estos elementos que constituyen el endometrio, son útiles para unificar criterios de fechado en las diferentes investigaciones, sin embargo presentan cierto grado de subjetividad; es por ello que en nuestro Departamento, hemos tratado de objetivizar estas variables cualitativas dándole un puntaje, lo que nos ha permitido conocer el grado de maduración endometrial, propuesta que ha sido útil, en investigaciones ya terminadas ( ).

La maduración glandular se clasifica en:

a. Respuesta Luminal: Luz no colapsada: 1, colapsada: 2 .

b. Respuesta Epitelial: Vacuolas ausentes: 1, subnucleares: 2 supranucleares: 3 , exhausta: 4 .

c. Respuesta Nuclear: ovales: 1, redondos: 2, poligonales: 3 , bizarros: 4 .

d. Atipia Nuclear: ausentes: 1 , escasos: 2 , frecuentes: 3, abundantes: 4 .

Total catorce puntos.

La maduración estromal se clasifica según los siguientes parámetros:

a. Predecidualización: ausente: 1 , perivascular: 2 , periglandular: 3 y total: 4 .

b. Respuesta Granulocítica: ausentes: 1, perivascular: 2, difusos: 3 , abundantes: 4 .

c. Hemorragias: ausente: 1 , perivascular: 2 , confluentes: 3 , total: 4 .

d. Edema: ausente: 1, leve: 2, moderado: 3, severo: 4 .

e. Respuesta Vascular: vasos ausentes: 1 , presentes: 2 , hiperplasia de capa media: 3 .

Para un total de 19 puntos, siendo el total de la maduración endometrial de 33 puntos. De lo anteriormente expuesto, se pueden obtener tres índices de maduración:

a. Glandular: Que se obtiene de dividir el puntaje total glandular del endometrio del paciente por 14.

b. Estromal: Se divide por 19.

c. Endometrial, por 33.

La presente revisión pretende resaltar la importancia del estudio histólógico del endometrio durante el estudio de la infertilidad, no sólo desde el punto de vista endocrino sino desde la patología uterina, crear el interés de interpretar adecuadamente los criterios histológicos, independientemente de nuestra condición de clínicos, como también reconocer parte de la patología orgánica comprometida en la infertilidad.

\section{BIBLIOGRAFIA}

1. Wentz AC. Endometrial biopsy in the evaluation of infertility. Fertil Steril 1980; 33: 121-124

2. Mc Neely MJ., Soules MR. The diagnosis of luteal phase deficiency: a critical review. Fertil Steril 1988; 50: 1-15.

3. Driessen F., Huliwerda PJ., Putte SCJ., Kremer J. The significance of dating an endometrial biopsy for the pregnosis of the infertile couple Int. J. Fertil 1980; 25: 112.

4. Sánchez F., Díaz C., Alfonso H., Correa L., Zuluaga M., Agudelo G. Análisis de correlación, sensibilidad y especificidad de la progesterona plasmática y el endometrio histológico con relación al cuerpo lúteo. Rev. Col. Obstet. Ginecol. 1991; 42 (Suplem): 52-53.

5. Rock JA., Zacur HA. The clinical management of repeated early pregnancy wastage. Fertil Steril 1983; 39: 123.

6. Wentz AC., Herbert CM III., Maxon WS., Hill Ga., Pittaway DE. Cycle of conception endometrial biopsy. Fertil Steril 1986; 46: 196-199.

7. Tsibris JCM., Fort FL., Cazenave CR., Cantor B., Bardawil WA., Notelovitz M., Spellacy WN. The uneven distribution of estrogen and progesterone receptors in human endometrium. J. Steroid Biochem 1981; 14: 997-1003.
8. Sánchez F., Devia G., Díaz C., Henao G., Mejía JM. Embarazos durante el ciclo de la biopsia de endometrio. Rev. Col. Obstet. Ginecol. 1989; 40: 93-97.

9. Rosenfeld DL., Garcia CR. Endometrial biopsy in the cycle of conception. Fertil Steril 1975; 26: 1088-1093.

10. Karow WG., Gentry WC., Skeels RF., Pagne SA. Endometrial biopsy in the luteal phase of the cycle of conception. Fertil Steril 1971;22:482495.

11. Rosenfeld DL., Garcia CR. Endometrial biopsy in the cycle of conception. Fertil Steril 1975; 26: 1088-1093.

12. Sánchez F., Morán C., Jácome E., Díaz C. Estudio sobre la existencia de un reflujo neuroendocrino que se inicia a nivel vaginal o cervical en la mujer. Rev. Latinoam. Esteril Fertil 1988; 2: 130-135.

13. Díaz C., Sánchez F., Correa L., Moscote L., Pineda G. Cambios histológicos del endometrio secretor humano secundarios al trauma. Rev. Colomb. Obst. Ginecol. 1991; 42 (Suppl) 45-46.

14. Bronson R., Hamada $Y$. The effect of prostaglandine $F_{2}$ alfa and $E$ on pregnancy in mice during implantation Fertil Steril 1978; 30: 354-361. 
15. Dallembach-Helweg GB. The Normal Histology of The Endometrium: in histopathology of the endometrium. Edit. Springer-Verlag: Berlin cuarta 4a. edition, 1987; 25-92.

16. Tabibzadeh SS., Satyaswaroop PG., Roa PN. Antiproliferative effect of interferon gama in human endometrial epithelial cells in vitro: potencial local Growth modulatory role in endometrium J. Clin. Endocrinol Metab., 1988; 67: 131-138.

17. Fraser IS. Mechanism of endometrial bleeding. Reprod Fertil Dev. 1990; 2: $193-198$.

18. Joshi SG., Roa R., Henriques EE., Raikar RS., Gordon M. Lutheal phase concentrations of a progestagen-associated endometrial protein (PEP) in the serum of cycling women with adequate or inadequate endometrium. J. Clin. Endocrinol Metab. 1986; 63: 1247-1249.
19. Bigazzi M., Nardi E., Bruni P., Petrucci F. Relaxin in human decidua. J. Clin. Endocrinol Metab. 1980; 51: 939-941.

20. Koay ESC., Bagnell CA., Bryant-Greenwood GO., Lord SB., Cruz AC., Larkin LH. Immunocytochemical localization of relaxin in human decidua and placenta. J. Clin. Endocrinol Metab. 1985; 60: 859-863.

21. Briant-Greenwood GD. Current conceptos on the role of relaxin. Res Reproduction 1985; 17: 1-2.

22. Noyes RW., Herting AT., Rock J. Doting the endometrial biopsy. Fertil Steril 1950; 1: 3-25.

23. Bayard E., Martín PM. Patología del endometrio in P. Mauvais-Jarvis, R. Sitruk - Ware, F. Flabric: Medicina de la Reproducción. Tora y SABarcelona 1985; 373-383.
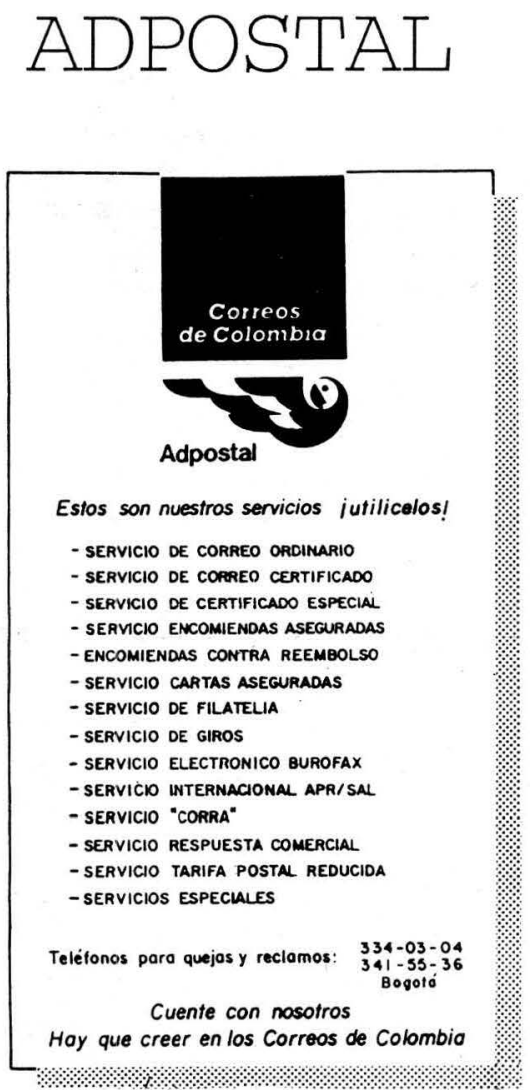